\title{
QUATRO OLHARES: ANÁLISE DE ALGUMAS CONTRIBUIÇÕES TEÓRICO-METODOLÓGICAS PARA A SOCIOLOGIA DA CULTURAE HISTÓRIA SOCIAL DA ARTE NO SÉCULO XX \\ Luiz Alberto Souza*
}

\begin{abstract}
Resumo
O estudo comparativo de alguns dos principais autores ligados à Sociologia da Cultura e à História Social da Arte aponta para a incrementação do debate no interior desses campos de pesquisa ao longo do século XX. Tal complexidade, por sua vez, expressou-se pela ampliação do universo documental, bem como pela introdução de novos temas, problemas e abordagens metodológicas em ambas as áreas do conhecimento. Este artigo apresenta e relaciona alguns pontos de vista em torno de duas importantes questões, tanto para historiadores da arte quanto para sociólogos da cultura: a discussão relativa à ideia de cultura e as diferentes compreensões acerca das relações entre formas estéticas e processos sociais. Para realizar essa discussão, analisa-se o uso das fontes, bem como os métodos empregados por quatro estudiosos identificados com tradições intelectuais mais ou menos diversas: Heinrich Wölfflin (18641945), Erwin Panofsky (1892-1968), Mikhail Bakhtin (1895-1975) e Timothy James Clark (1943).
\end{abstract}

Palavras-chave: Sociologia da Cultura; História da Arte; teoria e metodologia.

\footnotetext{
* Doutorando em História pela Universidade Federal de Santa Catarina (UFSC). Bolsista CNPq. Pesquisador junto ao Núcleo de Pesquisa História, Literatura e Sociedade - NEHLIS/UFSC. E-mail: luiz_alberto82@yahoo.com.br
} 


\section{Introdução}

\begin{abstract}
Por que se faz tanta questão de conferir à obra de arte - e ao conhecimento que ela reclama - essa condição de exceção, senão para atingir por um descrédito prévio as tentativas (necessariamente laboriosas e imperfeitas) daqueles que pretendem submeter esses produtos da ação bumana ao tratamento ordinário da ciência ordinária, epara afirmar a transcendência (espiritual) daqueles que sabem reconhecer-lhe a transcendência?
\end{abstract}

Pierre Bourdieu

Em As regras da arte, Pierre Bourdieu reivindica a possibilidade e a pertinência de "uma análise científica das condições de produção e da recepção da obra de arte" (BOURDIEU, 1996, p. 14). Nesse livro, o sociólogo, partindo de um posicionamento oposto ao da perspectiva estética tradicional, de inspiração kantiana, esclarece um dos principais pressupostos da Sociologia da Cultura e da História Social da Arte. A saber: a negação do princípio da inefabilidade da criação, apreciação e julgamento estético, a convicção de que essa ideia, tomada muitas vezes por postulado indiscutível, "é sempre e de muitas maneiras" uma concepção "superdeterminada" (OUTHWAITE, 1988, p. 740).

Assim, invertendo a premissa de Gadamer que diz ser a obra de arte "um desafio lançado à nossa compreensão, porque escapa indefinidamente a toda explicação e opõe uma resistência sempre insuperável' (GADAMER apud BOURDIEU, 1996, p. 12), podese dizer que, para o historiador e o sociólogo, a questão central não é propriamente a crítica ao princípio da "transcendentalidade" de um autor ou obra. Ou seja, não é a simples demonstração de que ambos são "produtos do seu tempo". E isto ocorre exatamente porque é esse o seu ponto de partida. $\mathrm{O}$ ponto de chegada, por sua vez, está em outro lugar. Para esses especialistas o problema, de fato, é compreender como a realidade social apresenta-se nas obras. Como "o externo (no caso, o social) importa, não como causa, nem como significado, mas como elemento que desempenha certo papel na constituição da estrutura [da obra], tornando-se, portanto, interno" (CANDIDO, 2000, p. 6).

Tal questão, é claro, não recebeu até hoje uma única resposta. Neste artigo, quero discutir, a partir do tratamento dado a dois temas, algumas de suas soluções possíveis. Desse modo, meus eixos aqui são: 1) as distintas compreensões da ideia de cultura; e 2) as diferentes maneiras de relacionar formas estéticas e processos 
sociais. Assuntos que, tratados desde pontos de vista mais ou menos diversos, ilustram parte da riqueza teórico-metodológica e vivacidade dos debates travados no interior da Sociologia da Cultura e História Social da Arte nos últimos cem anos. Assim, para compor esse painel, escolhi quatro autores e quatro obras que, a meu ver, são capazes de proporcionar uma boa amostra dessas discussões: o historiador da arte suíço Heinrich Wölfflin; o historiador da arte alemão Erwin Panofsky; o linguista russo Mikhail Bakhtin e, finalmente, o historiador inglês Timothy James Clark.

\section{Breve itinerário de um debate}

Desde fins do século XVIII e durante todo o século XIX, uma parte importante da intelectualidade européia sentia forte necessidade de repensar a história cultural daquele continente. A “metamorfose dos valores" (BERMANN, 2010, p. 136), tão características da modernidade capitalista, transmudava tudo, incluindo a arte e os seus princípios. Em meio à crise representada pelo advento de novos movimentos estéticos como o Romantismo, Realismo, Naturalismo, Impressionismo e Expressionismo, questionavam-se os antigos parâmetros do que, até então, era definido como "belo" e propunham-se reavaliações críticas do cânone europeu. A "arte moderna" trazia consigo, portanto, a problemática da história da arte. Um arcabouço de questões complexas entre as quais se impunha, também, a das relações entre a arte, vida e destino das sociedades (BASTIDE, 1971, p. 3-33).

Imerso nesse contexto, o compositor alemão Richard Wagner formulava, assim, a necessidade de repor a arte europeia em uma perspectiva histórica:

Precisamos nos convencer definitivamente de que nossa história hoje é feita pelos mesmos seres humanos que também fizeram um dia as obras da arte grega. Mas tendo aceito esse ponto, nossa tarefa é então descobrir o que é que transformou esses seres humanos de forma tão fundamental a ponto de agora só conseguirmos produzir o que sai das industrias de luxo, onde antes se criavam obras de arte. (WAGNER apud HOBSBAWM, 2005, p. 383).

Alguns dos principais esquemas analíticos utilizados pelos sociólogos e historiadores da arte e da cultura ao longo do século XX foram, em grande medida, tributários desses primeiros 
1 A corrente de estudiosos em História da Arte conhecida por "Escola de Viena" iniciouse na Universidade de Viena, capital do então Império Austro-Húngaro, e tem na obra de Rudolf Eitelberger, um dos seus trabalhos pioneiros. Seus representantes, entre eles Burckhardt e Alois Riegl, entendendiam a História da Arte como uma disciplina autônoma assentada por sobre uma base "científica", distanciando-a de julgamentos históricos a partir de questões de preferência estética e "gosto". Busca, para tanto, a criação de conceitos rigorosos de análise por meio do qual todas as obras de arte pudessem ser compreendidas. Sobre a Escola de Viena e a Teoria da Visibilidade Pura, cf. BARROS, José D'Assunção. Alois Riegl e a visibilidade pura: revisitando a obra de um historiador da arte de fins do século XIX. Cultura Visual, n. 18, p. 61-72, dez. 2012. esforços de reinterpretação do passado artístico europeu. Obras como Da literatura considerada em suas relações com as instituições sociais (1800), de Germaine de Staël, História da Literatura Inglesa (1864), de Hippolyte Taine, Do principio da arte e de sua destinação social (1865), de Pierre-Joseph Proudhon, ou a A cultura do Renascimento na Itália (1860), de Jacob Burckhardt são apenas alguns exemplos dessas tentativas de releituras do passado do patrimônio artístico europeu, desta vez, em íntimas conexões com outras dimensões da realidade humana.

$\mathrm{E}$ é à herança intelectual de um desses precursores que o pensamento de Heinrich Wölfflin associa-se diretamente. Discípulo de Burckhardt, Wölfflin formulou um conjunto objetivo de critérios para as classificações da história da arte. Em livros como Conceitos Fundamentais da História da Arte, cuja primeira edição é de 1915 , esse autor desenvolveu uma história da arte compreendida, basicamente, como uma história dos estilos (WÖLFFLIN, 2000). Tal perspectiva focalizava, por sua vez, o que daria sentido unitário a um conjunto de manifestações estéticas aparentemente singulares. O que aproximaria artistas que, tradicionalmente, eram compreendidos como "gênios absolutos", dotados de singularidades irredutíveis. Nesse sentido, segundo o seu ponto de vista, o "estilo individual" estaria para o "estilo de época”, assim como a caligrafia estaria para a gramática. Isto é, o modo individual de expressão artística seria a manifestação particular de um conjunto de prescrições e regras que determinam o uso considerado correto de certo meio sistemático de comunicar ideias ou sentimentos por meio de signos convencionais (no caso, por meio de signos gráficos). A obra de arte condensaria, portanto, ao mesmo tempo, o estilo individual e o diálogo com a tradição (o "contexto" de uma obra). Assim, desde a perspectiva analítica, o que importaria para Wölfflin seriam as particularidades de composição apresentadas por um determinado objeto estético.

A abordagem formalista de Wölfflin fundamentava-se nos princípios teóricos da chamada Escola de Viena de Historiografia da Arte e é uma das principais expressões da Teoria da Visibilidade Pura (BARROS, 2011). ${ }^{1}$ Para os autores ligados a essa corrente, a arte teria uma história própria, que não poderia ser subordinada à da economia, política ou da língua. A História da Arte, mais do que um conhecimento acessório ou dependente, seria uma disciplina com suas próprias particularidades, que se justificaria por si mesma. 
Em sua obra, Wölfflin procurava realizar uma história da arte atenta às qualidades distintivas fundamentais próprias do trabalho estético. Sua proposição dava-se no sentido de estabelecer as bases teóricas de uma história da arte que não coincidisse, necessariamente, com a história de um "povo" ou de uma "nação". Sua atenção voltava-se para o contexto exclusivo de produção da arte, o que, por sua vez, convida aos seus estudiosos a pensarem certas questões que não são identificáveis em outros fatos ou situações (políticas, econômicas, sociais). Ou seja, a história da arte, por ser um processo particular, exigiria indagações exclusivas, apenas condizentes consigo mesma.

Esse entendimento, por sua vez, levou Wölfflin a deduzir certos fenômenos acerca da dinâmica do desenvolvimento histórico da arte. Para ele, assim como as línguas, por exemplo, teriam uma história própria, a arte também se transformaria de acordo com suas leis, ritmos e regras. Também a arte realizaria a sua própria "evolução". Termo este que, em Wölfflin, não implica progresso (na acepção de desenvolvimento do inferior para o superior, do mais simples ao mais complexo), mas movimento, transformação, mudança, deslocamento. Caberia, por conseguinte, ao historiador estar atento a esses ritmos próprios e não confundilos com os de outros aspectos da totalidade social.

Destarte, além de um entendimento mais apurado acerca dos modos particulares de produção das obras no tempo, a análise crítica proposta por Wölfflin abriu também a possibilidade de perscrutar a forma de percepção de uma criação artística em um determinado momento histórico. Para o autor, a representação e percepção não seriam fenômenos isolados e independentes, mas processos em interação. Novas formas de representação implicariam, nesse sentido, em novos modos de olhar. Segundo o teórico, "em cada novo estilo de visão cristaliza-se um novo conteúdo do mundo" (WOLLFLIN, 2000, p. 334). Essa observação de Wölfflin, contudo, precisa ser entendida de forma complexa (isto é, não mecânica ou generalizável). A história da arte, segundo o seu argumento, se articularia com uma história da percepção, mas ambas não coincidiriam. Também obedeceriam a temporalidades próprias. Assim como a história da arte não coincidiria com a história política, econômica ou social, a história da visão não se ajustaria de maneira perfeita à história das formas.

A obra de Wölfflin, centrada no estudo dos padrões de representação e em tendências de expressão, tornou-se uma das 
mais importantes contribuições à História da Arte no século XX. Sua abordagem é uma das bases teóricas de importantes sínteses históricas sobre a chamada "Arte Ocidental", escritas ao longo do século passado. Entre elas A História da Arte, de Ernst Gombrich, compêndio publicado, originalmente, em 1950 e, até hoje, muito lido e discutido nos cursos de formação em Artes Visuais em diversos países. Não obstante, a despeito do caráter inovador que a História dos Estilos proposta pela Escola de Viena representaria no final do século XIX, bem como da grande difusão que encontraria, sobretudo na primeira metade do século $\mathrm{XX}$, a orientação radicalmente formalista de Wölfflin não se manteve isenta de críticas e retificações. E, uma delas, seria a representada pelo trabalho de Erwin Panofsky.

Assim como Wölfflin, Panofsky (2001) também foi discípulo de um erudito ilustre: Aby Warburg. E, tal qual Wölfflin, também foi um dos maiores expoentes, no século XX, de certa tradição de pensamento acerca da História da Arte que tem as suas raízes no contexto intelectual europeu do final do século XIX.

Autor de uma extensa bibliografia, alguns dos livros mais influentes de Panofsky são Arquitetura Gótica e Escolástica (1951) e Significado nas Artes Visuais (1955). Trabalhos onde, sucessivamente, elabora e aplica de maneira exemplar aquela que talvez seja a sua maior contribuição à teoria e metodologia da história da arte no século XX: o método iconológico (ou simplesmente "iconologia”).

Apresentado de maneira esquemática no capítulo "Iconografia e iconologia: uma introdução ao estudo da arte da Renascença” (ensaio publicado, originalmente, em 1939), do livro Significado nas Artes Visuais (2001), a concepção do método iconológico foi, realmente, o desenvolvimento de alguns princípios já elaborados por Aby Warburg no começo do século XX. (MOLINA, 2010). Sem embargo, é a partir da contribuição de Panofsky que o método iconológico tornou-se o eixo principal de um novo paradigma de abordagem acerca das obras de arte. Vejamos, pois, as linhas gerais da argumentação exposta neste ensaio.

Segundo Panofsky, existiriam três níveis de análise de uma obra: o primário, o secundário e o intrínseco. No primeiro nível de compreensão (também chamado "natural") o entendimento se orientaria por meio da familiaridade do observador para com determinados objetos e fatos representados na obra. Ou seja, a percepção do significado se fundamentaria, tão somente, na 
"experiência prática" do analista. A compreensão primária, para Panofsky, seria o resultado daquela etapa a qual este chamava de "descrição pré-iconográfica". Isto é, o procedimento de enumeração das "formas puras" ou dos "motivos" artísticos (padrão geral de cores, linhas e volumes que constitui o mundo captado pela visão).

Já no segundo nível de compreensão ("convencional”), o entendimento se orientaria por meio do conhecimento básico de certos signos e significados próprios de uma determinada cultura. A compreensão secundária é o resultado daquela etapa explicativa a qual Panofsky chama de "análise iconográfica". A análise iconográfica pressupõe, consequentemente, a familiaridade do pesquisador com temas específicos e conceitos. Tal familiaridade, por sua vez, seria adquirida, por exemplo, por meio de fontes literárias, contato com outras obras ou mesmo pela tradição oral.

Finalmente, o terceiro nível de compreensão seria aquele ao qual Panofsky chamava de "intrínseco" ou de "conteúdo". Neste, o entendimento de uma obra incorporaria observações referentes à época, nacionalidade, classe social, tradições intelectuais etc. Seu alcance ocorreria como resultado da "interpretação iconológica". Segundo o autor, a interpretação iconológica (ou "iconologia") constituiria o nível de compreensão mais avançado, mais revelador do significado estético. Seria por meio dele que as características composicionais e iconográficas de uma ou de um conjunto de obras de arte poderiam ser percebidas como sintomas de uma "atitude básica" de uma nação, de um período, classe social, crença religiosa ou filosofia predominante em uma época.

Como exemplo prático, tem-se o estudo que Panofsky realizou sobre a origem do Gótico. Intitulado Arquitetura Gótica e Escolástica (2001), esse texto foi apresentado, pela primeira vez, como uma conferência proferida em 1948, no Saint Vincent College, na Pennsylvania. Anos depois, em 1951, uma versão revista e acrescida de notas foi publicada em livro. Desde então esse trabalho vem suscitando debates e controvérsias, tanto pelo que propõe acerca da história da arte medieval e suas interpretações sobre o Gótico, quanto pelas questões metodológicas que suscita.

A problemática básica desenvolvida nesse livro pode ser sintetizada da seguinte maneira: afinal, o que dá unidade interna a um período histórico específico? Como se estabelecem as analogias que aproximam fenômenos tão distintos como a arte, literatura e filosofia produzidos em mesmo tempo e espaço? 
A resposta dada pelo autor deriva da sua investigação acerca das relações que se estabeleceram entre a arquitetura gótica e a filosofia escolástica na França do final da Idade Média. Para o autor, há um desenvolvimento sincrônico entre o estilo gótico e a escolástica. Tal simultaneidade, por sua vez, se explicaria pelo compartilhamento, por parte considerável de teólogos e arquitetos, dos mesmos hábitos mentais.

Segundo Panofsky, é certo de que há equivalência entre a Escolástica plenamente consolidada como filosofia e o Gótico enquanto estilo arquitetônico em fase inicial de desenvolvimento. Não obstante, tal evolução, mais ou menos sincrônica entre ambos, se fundamentaria em um vínculo ainda mais concreto do que o simples paralelismo. Para o autor, o que definiria a conexão entre as duas manifestações seria uma verdadeira relação de causa e efeito.

Sendo assim, a certa altura da sua argumentação, Panofsky apresenta o conceito de "hábito mental". Retomando a sua significação escolástica, o autor define "hábito mental" como o "princípio que rege a ação", uma ideia - ou um conjunto de ideias - tão amplamente difundido, tão impregnado numa certa cultura, que os indivíduos a operariam de forma quase "natural", inconsciente. Nesse sentido, a Escolástica teria atuado, entre os séculos XII e XIII, na região do entorno de Paris, como uma força capaz de instituir alguns desses novos modos de pensar e agir.

De acordo com o autor, nessa época, a Escolástica monopolizava os espaços de formação intelectual (universidades) dos quais partiam não só os teólogos, mas também os arquitetos. No mais, nesse período, as ideias escolásticas estavam em plena circulação no próprio meio social mais amplo. Nesse ambiente, era comum que mesmo os que não tivessem lido os filósofos e teólogos pudessem tomar contato com as suas concepções mais fundamentais. As mudanças na vida social (urbanização e organização ainda não tão especializada do trabalho) influenciariam esse processo de circulação e difusão das ideias escolásticas, tornando-a quase onipresente nos limites do entorno intelectual de Paris.

Foi assim, portanto, que, nesse período, estabeleceuse um novo nexo entre um conjunto de práticas artísticas e de representações mentais em um dos centros do mundo cristão ocidental. Orientando processos de estruturação de catedrais e de summas (tratados sistemáticos acerca de um determinado 
conjunto de conhecimentos), princípios escolásticos como os da concordantia e da manifestatio estabeleceram-se como verdadeiros hábitos mentais que se expressavam em diversos âmbitos da cultura erudita. Algo que se verificava não só nas formulações teológicas ou construções arquitetônicas, mas que, após certo período, materializava-se até mesmo na literatura de autores como os poetas italianos Dante e Petrarca. Isto posto, a julgar por todas essas evidências, a Escolástica se caracterizaria como a grande chave de compreensão de boa parte do pensamento e sensibilidade medieval.

Tais interpretações não passaram sem polêmica. Sem embargo, a despeito de todas as controvérsias em torno das principais teses do livro Arquitetura gótica e escolástica, este acabou tornando-se um modelo de aplicação do método iconológico. $\mathrm{O}$ esforço de Panofsky em demonstrar que a relação que se estabeleceu entre o Gótico e a Escolástica não teria sido a de simples paralelismo, mas que, de fato, a Escolástica definiu as condições de produção do estilo arquitetônico gótico, ilustra, de modo exemplar, a ideia de iconologia. Nele encontramos um dos exemplos melhor acabados de busca por aquilo que Panofsky chamava de atitude básica de um período.

Vê-se, portanto, que há um contraste entre Wölfflin e Panofsky. Ao atribuir às dimensões social e cultural uma das bases interpretativas da criação artística, o método iconológico de um contraria a abordagem estritamente fundamentada na observação dos padrões estilísticos defendida pelo outro. $\mathrm{O}$ método de Panofsky aponta, nesse sentido, para uma interpretação da obra de arte que a compreenda em termos de diálogo entre as diversas esferas da realidade humana. Supera o ponto de vista de Wölfflin no que diz respeito à compreensão das relações entre a emergência de novas formas estéticas e os diferentes processos sociais. Tal entendimento acerca das ligações entre arte e sociedade fazem de Panofsky - bem como da tradição intelectual da qual ele é representante - um dos historiadores da arte mais influentes nos campos da Sociologia da Cultura e da História Social da Arte. Assim, como exemplos de autores contemporâneos tributários da sua obra e pensamento, podemos citar o sociólogo francês Pierre Bourdieu (cujo conceito de habitus dialoga intimamente com a noção de "hábito mental" de Panofsky) e o historiador italiano Carlo Ginzburg (cuja formação, inclusive, passou pelo Instituto Warburg). 
Outra corrente crítica ao ponto de vista representado por Wölfflin - mas também em muitos sentidos a de certos aspectos próprios à obra de Panofsky - é aquela identificada com o chamado "marxismo ortodoxo". Representada por autores como Franz Mehring, Gueorgui Plekhanov e, em grande medida, György Lukács, a perspectiva estética preconizada por essa tendência pode ser sintetizada na seguinte afirmação: "a arte de qualquer povo tem sempre, (...), uma íntima conexão causal com a sua economia" (PLEKHANOV apud BOTTOMORE, 1988, p. 18). Acusados de "formalismo" (no sentido de abstraírem a obra do seu contexto social de produção), os autores ligados à Escola de Viena foram, por sua vez, duramente criticados pelos historiadores influenciados por essa tendência do marxismo. Foi este o caso, por exemplo, de Arnold Hauser, um historiador $\mathrm{da}$ arte húngaro que preconizava, sobretudo, a ênfase nas determinantes sociais e econômicas como o principal aspecto analítico da compreensão estética. Não obstante, se hoje obras como História Social da Arte e da Cultura (1951) - livro no qual Hauser polemizava diretamente com Wölfflin - tem perdido progressivamente o seu apelo, outro autor, este também orientado pelo princípio básico de que a arte é determinada "em última instância" pelas estruturas econômicas e sociais de uma época, vem sobrevivendo com muito mais vigor do que Hauser. Refiro-me aqui ao linguista e filósofo russo Mikhail Bakhtin, um pensador altamente seminal e que estendeu a sua influência para muito além dos limites dos círculos marxistas.

Segundo o historiador inglês Peter Burke (2005, p. 71), Bakhtin foi "um dos teóricos culturais mais originais do século XX". Realizador de uma obra extensa e influente, as suas ideias alcançaram grande penetração em muitas disciplinas e linhagens teóricas (Marxismo, Estruturalismo, Teoria Literária, História, Filosofia, Antropologia, Psicologia...). Sua tese - A Cultura Popular na Idade Média e no Renascimento: o contexto de François Rabelais (1941) - ganhou projeção mundial desde a sua primeira tradução francesa realizada nos anos 1960. Esse livro, por sua vez, tornou-se um clássico, entre outras coisas, por enriquecer extraordinariamente, na segunda metade do século XX, o debate acerca da cultura. Foi a partir da difusão dessa obra no Ocidente que noções e conceitos como "dialogismo", "polifonia", "heteroglossia" e "carnavalização" tornaram-se expressões comuns no campo semântico das Ciências Humanas e dos Estudos Literários. 
Por sua vez, um dos aspectos decisivos para a compreensão de A Cultura Popular... é a percepção do tipo de registro lógico com o qual opera Bakhtin ao longo de toda a sua argumentação. Nesse livro, o teórico desenvolve a sua reflexão de maneira dual, a partir de uma série de dicotomias (oficial/não oficial, seriedade/alegria, dominação/contradominação, dogmatismo/ liberdade, desigualdade/igualdade, morte/vida, classe/povo). Como consequência, tal modelo acaba organizando a formulação bakhtiniana a respeito do fenômeno cultural. Para esse autor, a cultura não seria uma realidade una, mas cindida entre "erudito" e "popular". Dimensões, por sua vez, opostas e essencialmente diversas. E é sobre essa modalidade prévia de classificação que o autor fundamenta as suas teses acerca de François Rabelais e sua obra.

O interesse de Bakhtin por Rabelais, por sua vez, justifica-se pelo modo como o teórico compreende a relação possível entre um autor e a cultura popular. Para o autor, Rabelais falaria em nome dessa cultura, seria uma espécie de porta-voz do "povo". Nesse sentido, textos como Gargantua e Pantagruel, por exemplo, corresponderiam a uma autêntica formalização da própria cultura popular. Assim, de certo modo, pensar a literatura de Rabelais corresponderia ao mesmo que pensar a cultura popular da Europa medieval. Aqui temos, portanto, a percepção de uma relação direta entre arte e sociedade. Analisar Rabelais, sob a óptica de Bakhtin, seria o equivalente a analisar a realidade da cultura popular. $\mathrm{O}$ escritor tornar-se-ia importante aos olhos do analista pelo tanto que a sua obra contivesse de documental, pela sua natureza testemunhal diante da realidade objetivada enquanto conteúdo expresso na obra.

Tal modo de pensar, por sua vez, pressupõe também a divisão estanque entre texto e contexto. A literatura, para Bakhtin, não seria ela mesma história. A literatura (ou a arte) seria, de fato, um reflexo da realidade "externa" à criação. Não constituiria, por conseguinte, uma realidade autônoma, com existência própria. Em Bakhtin, a ideia de contexto ignora o diálogo com outros autores e obras e reafirma, por sua vez, a convicção de que a arte seria produto das condições sociais e econômicas. Dessa maneira, o sentido de "contexto", em Bakhtin, não teria a ver (como em Wölfflin e Panofsky) com os artistas e obras, mas, sobretudo, com as bases materiais que fundamentavam a vida social da Idade Média e do Renascimento. Bakhtin despreza, portanto, as 
“regras da arte”. Seu Rabelais seria, além disso, um personagem carismático na acepção weberiana do termo. Sua performance enquanto artista não se explicaria pela história, mas pela posse de um determinado "dom”. Pela sua aptidão inata para fazer algo. Desse modo, enquanto ser de exceção, Rabelais encontrar-se-ia fora do ordinário. Sua arte se apartaria, em grande medida, do seu próprio ambiente intelectual.

Portanto, percebendo o artista como um tipo de "antena sensível do seu tempo", Bakhtin parece compreender o diálogo literário de Rabelais, o seu contexto propriamente intelectual, como algo secundário. Sob esse viés de abordagem, as peculiaridades da criação literária, a intertextualidade, o lugar de um autor em uma determinada tradição cultural não seriam mediações realmente relevantes como dados de análise.

Além disso, a abordagem de Bakhtin possui, também, um caráter essencialista bastante acentuado. $\mathrm{O}$ aspecto essencialista do seu pensamento manifesta-se, sobretudo, na sua compreensão de povo e de cultura popular. Para o autor, o "povo" tem um conjunto de qualidades, propriedades e atributos universais que caracterizam a sua natureza. Tal essência se fundamentaria na visão grotesca do mundo e se formalizaria em uma manifestação cultural específica: o carnaval.

O grotesco é definido, em Bakhtin, pela falta de divisão entre os elementos. A cultura popular seria grotesca pela indistinção subjacente a ela. Segundo o autor:

Ela [a linguagem carnavalesca] caracteriza-se, principalmente, pela lógica original das coisas "ao avesso, "ao contrário", das permutações constantes do alto e do baixo ("a roda”), da face e do traseiro, e pelas diversas formas de paródias, travestis, degradações, profanações, coroamentos e destronamentos bufões. (BAKHTIN, 2002, p. 10).

A concepção grotesca do mundo seria, de acordo com Bakhtin, o que dá sentido unitário e originalidade à cultura popular. Esse conjunto de traços psicológicos e espirituais que caracterizariam o povo seria, por sua vez, trans-histórico. Ou seja, se manteria inalterado ao longo do tempo. Seria isto o aspecto fundamental da cultura popular, o seu mais básico, mais central, a sua característica mais importante. Seria o grotesco a essência que daria significado à cultura do povo. Uma cultura que, por sua vez, teria no riso carnavalesco a sua maior expressão. 
No mais, para o linguista russo, a cultura popular seria sempre coletiva e contrária ao status quo. Compreender essa percepção manifesta por Bakhtin nos possibilita captar a significação política que este atribui ao riso em sua obra. Para o autor, o riso carnavalesco aspiraria sempre à instauração de uma nova ordem, ao advento de uma nova vida. A sua atenção à comicidade popular lhe parece central tendo em vista que, a seu ver, esta conteria em germe uma força política visceralmente revolucionária. Para Bakhtin, o riso do povo é importante, pois, na sua expressão satírica, grotesca, carnavalesca haveria, também, um desafio sempre reposto aos poderes instituídos. A afirmação do subalterno diante do dominador.

A reflexão de Bakhtin é, sob diversos aspectos, muito instigante e original (sobretudo se levarmos em conta o contexto político e intelectual no qual foi produzida). Não obstante, a despeito das suas inúmeras qualidades positivas, faz-se necessário notar que todos os tipos de essencializações e universalizações são procedimentos altamente problemáticos desde um ponto de vista metodológico. Isto porque, ao atribuirmos a qualquer grupo social (seja ele uma classe, etnia, nacionalidade ou gênero) qualquer tipo de aspecto inerente e imutável estaremos, de fato, negando a historicidade própria a todos os fenômenos humanos. Ademais, a lógica dicotômica, o jogo de opostos, realizado por Bakhtin, transforma a diferença em unidade e faz do "povo" tábula rasa. Reduz-lhe a uma única e mesma coisa (sem hierarquias, sem contradições). Assim, ao sustentar uma visão estanque e monolítica de cultura popular, Bakhtin nos dá a entender que a sua análise fundamenta-se muito mais em um esquema concebido a priori do que em uma análise atenta das fontes. Lugar onde a multiplicidade e a transformação, de algum modo, invariavelmente, são expressadas.

Contudo, há um aspecto particularmente precioso na reflexão de Bakhtin: a sua noção geral de cultura. Tal característica é evidenciada quando realizamos o contraste entre o linguista russo e os dois historiadores anteriormente apresentados. Se, a despeito das suas diferenças, tanto Wölfflin quanto Panofsky, eram pensadores estritamente interessados naquilo que poderíamos chamar de a "grande tradição", e permaneciam intimamente ligados a uma linhagem intelectual que pressupunha como "cultura" apenas as "altas produções do espírito", as "obrasprimas" da arte, literatura, filosofia e ciência (BURKE, 2005, p. 
16), Bakhtin, por sua vez, aponta para outra concepção do termo: uma definição mais "antropológica", que torna o "popular", o "folclórico", como algo, de fato, em conexão com a "alta cultura" e que, de algum modo, também a constitui. Esse entendimento, apesar das insuficiências da formulação bakhtiniana, ajudaria a abrir caminho e dar subsídios teóricos para trabalhos importantes nos campos da Sociologia da Cultura e da História Social da Arte. Uma trilha que seria repisada e estendida por leitores críticos de Bakhtin. Caso, por exemplo, do já citado Peter Burke.

Em suma, se sob muitos ângulos a obra de Bakhtin permanece atual e relevante, sob outros aspectos sua abordagem parece superada inclusive por experiências realizadas no interior da própria tradição intelectual na qual ela se insere. A título de exemplo, farei menção ao trabalho de um autor que me parece mesclar o que há de melhor em Wölfflin, Panofsky e no próprio Bakhtin. A saber: a atenção à particularidade formal das obras (Wölfflin), a percepção dialética entre criação artística e processos sociais os mais diversos (Panofsky) e uma compreensão complexificada de cultura (Bakhtin). Refiro-me, aqui, ao inglês Timothy James Clark, um historiador da arte que, bebendo nas fontes mais heterodoxas da linhagem marxista (em particular na dos "frankfurtianos" Theodor Adorno e Walter Benjamin), realiza uma análise bastante diversa daquela desenvolvida pelo também marxista - e também heterodoxo - Mikhail Bakhtin.

A primeira coisa que podemos dizer sobre a abordagem de Clark é que ela foge de qualquer esquematismo que vê na arte o reflexo da sociedade. Seu trabalho com as fontes é um exemplo de análise que percebe na própria forma estética os traços das relações sociais nas quais autor e obra estão imersos. Sua perspectiva metodológica, portanto, supera as concepções dicotômicas tradicionais entre texto e contexto, cultura e sociedade, forma e conteúdo. Para esse autor, a criação artística não constituiria simples "reflexo" do seu tempo. O conteúdo social, a história, não surgiria no texto, nas imagens, nas formas, de uma maneira direta e evidente. A obra seria uma mediação entre a experiência social dos produtores e os processos mesmos de composição estética. Logo, para Clark, interessaria menos o que uma obra diz e mais 0 modo como ela diz. O significado social de um poema, romance, quadro, não estaria fora do texto ou da pintura - no seu exterior ou "contexto histórico" - mas, pelo contrário, estaria inscrito na própria obra, na maneira como ela se apresenta. 
Exemplar desse tipo de abordagem, que toma a obra como mediação, e não como reflexo, foi o estudo que Clark realizou sobre os impressionistas franceses. No seu livro, A pintura da vida moderna (2004), de 1984, o autor examinou alguns dos principais quadros referentes à produção daquele grupo. Assim, dentre algumas obras icônicas, o historiador deteve-se ao famoso Olympia, de Édouard Manet. Pintada em 1863, Olympia, como se sabe, é a representação de uma mulher nua - supostamente uma prostituta parisiense -, deitada em uma cama, fitando, diretamente e com olhar de desafio, o expectador do quadro. A composição de Manet foi inspirada na Venus de Urbino (1538), do renascentista Ticiano, que, por sua vez, teve como referência a obra Venus de Giorgione (c. 1510). A tela foi a primeira obra impressionista aceita no Salon de Paris em 1865 - a mais importante exposição de arte de toda a Europa - e, na época, causou tremendo escândalo.

Definida como "pornográfica" por parte do público e de "mau gosto" pela crítica, a péssima recepção de Olympia é usualmente interpretada pelos historiadores da arte como devida às inovações técnicas que apresenta, bem como ao seu conteúdo relativamente transgressor considerando-se os padrões morais da burguesia parisiense. Não contrariando essas leituras, a análise de Clark, porém, as complexificou e encontrou na fatura estética da própria obra e no impacto causado por ela, sobretudo os sinais de uma época em transformação.

Clark percebe nexos entre aspectos do processo de modernização industrial ocorrido nos grandes centros europeus do século XIX - como a Paris de Manet - e a emergência de novos padrões de expressão artística. Nesse sentido, a sua análise de Olympia procurou relacionar o quadro às grandes transformações sociais decorrentes da reformulação do espaço urbano ocorridas na capital francesa entre as décadas de 1850 e 1870 . Para o autor, as reformas urbanas de Paris, de certa maneira, teriam comprometido os antigos referenciais de classe com os quais as pessoas estavam tradicionalmente habituadas. Para ele, Haussmann, o então prefeito do departamento do Sena, ao promover melhorias nas manobras militares, assim como na circulação e na higienização da capital francesa, teria acabado, também, por provocar indefinições sobre antigos referenciais de classe.

A demolição de inúmeras vias pequenas e estreitas, residuais da cidade medieval, a criação de imensos boulevards organizadores do espaço urbano, assim como jardins e parques, 
teria comprometido as antigas determinações de fronteiras que marcavam as diferenças sociais. A confusão entre bairros burgueses e proletários instaurou-se e, com isso, as clivagens de classe deixaram de ter a distribuição do espaço como um dos seus fatores de efetivação. Nas ruas, banqueiros e mendigos passaram a compartilhar as mesmas calçadas, os mesmos parques, os mesmos cafés. As desigualdades coabitavam. Os antigos marcadores sociais desapareciam e, nesse processo, outros eram inventados.

No âmbito das artes, a ambiguidade presente em obras como Olympia seria, pois, o registro dessa crise. A forma estética materializaria em si o conteúdo social, e não apenas o representaria enquanto motivo. $\mathrm{O}$ mal-estar provocado pelo quadro não se resumiria, por consequência, apenas à nudez da mulher, mas à exposição da classe da qual Olympia era o retrato. A representação de Olympia é a de uma prostituta típica de um bordel parisiense. Não a de uma personagem, um tipo idealizado, como as cortesãs figuradas até então pelos pintores acadêmicos. $\mathrm{O}$ espectador que olhasse o quadro deparar-se-ia, com efeito, com a imagem de uma mulher identificável como uma prostituta, uma representante da classe proletária. Desse modo, do ponto de vista da crítica, Olympia apresentava-se como incompreensível, ou "indescritível", simplesmente porque a sua imagem explicitava aquilo que não podia ser verbalizado naquele espaço, daquele modo, por aquelas pessoas, pertencentes àquela sociedade. Nesse quadro, Manet ousava, não só no que se referia à experimentação técnico-pictórica ou à moralidade, mas, sobretudo, no que tangia aos valores políticos e sociais atribuídos à arte. Nele, o pintor discorria sobre o impronunciável. Deixando de lado qualquer estratégia de dissimulação, explicitava as marcas do grupo social a qual pertencia a sua modelo. E isto em pleno Salon de Paris, um dos centros nevrálgicos da "boa consciência" burguesa européia. Olympia formalizava, dessa maneira, uma nova relação entre as classes que se baseava em certo controle do que podia ou não ganhar visibilidade na esfera pública.

\section{Considerações finais}

Este artigo realizou o estudo comparativo de alguns dos principais autores ligados à Sociologia da Cultura e História Social da Arte. Nele, buscou-se enfatizar algumas das principais contribuições de Heinrich Wölfflin, Erwin Panofsky, Mikhail 
Bakhtin e Timothy James Clark no esforço coletivo de incrementação do debate acerca dos mecanismos que orientam as múltiplas relações entre arte e sociedade. Sua seleção foi, obviamente, incompleta. O conjunto de pensadores e obras aqui analisadas é, em verdade, produto de uma escolha mais ou menos arbitrária. Além desses, muitos outros nomes poderiam ter sido elencados com igual proveito (Nicolaus Pevsner, Martin Warnke, Norbert Elias, Erich Auerbach...). Não obstante, a título de amostra, acredito que este trabalho tenha cumprido minimamente o seu objetivo. A saber, o de ilustrar o quadro altamente complexo que representou, nos últimos cem anos, a ampliação do universo documental e a introdução de novos temas, problemas e abordagens metodológicas no seio dessas duas áreas do conhecimento.

\section{Referências}

BARROS, José D’Assunção. Alois Riegl e a visibilidade pura: revisitando a obra de um historiador da arte de fins do século XIX. Cultura Visual, n. 18, p. 61-72, dez. 2012.

BASTIDE, Roger. Arte e sociedade. 2. ed. São Paulo: Companhia Editora Nacional/Editora da USP, 1971.

BAKHTIN, Mikhail. A Cultura Popular na Idade Média e no Renascimento: o contexto de François Rabelais. 5. ed. São Paulo: Hucitec/ Annablume, 2002.

BERMAN, Marshall. Tudo o que é sólido desmancha no ar: a aventura da modernidade. São Paulo: Cia. das Letras, 2010.

BOURDIEU, Pierre. As regras da arte: gênese e estrutura do campo literário. São Paulo: Cia. das Letras, 1996.

BURKE, Peter. O que é história cultural? Rio de Janeiro: Jorge Zahar Ed., 2005.

CANDIDO, Antonio. Literatura e Sociedade. São Paulo: T. A. Queiroz; Publifolha, 2000.

CLARK, Timothy James. A pintura da vida moderna: Paris na arte de Manet e de seus seguidores. São Paulo: Companhia das Letras, 2004. 
HOBSBAWM, Eric. A Era do Capital 1848-1875. 11. ed. São Paulo: Editora Paz e Terra S/A, 2005.

MOLINA, Lucas Giehl. Da prática à teoria: o método iconológico de Erwin Panofsky (1921, 1939, 1955). 2010. 41 f. Trabalho de Conclusão de Curso (Graduação em História) - Curso de História, Universidade Federal do Rio Grande do Sul, Porto Alegre. 2010.

OUTHWAITE, William; BOTTOMORE, Tom. (Org.). Dicionário do pensamento social do século XX. Rio de Janeiro: Jorge Zahar Editor Ed., 1996.

OUTHWAITE, William. (Org.). Dicionário do pensamento marxista. Rio de Janeiro: Jorge Zahar Editor, 1988.

PANOFSKY, Erwin. Arquitetura Gótica e Escolástica: sobre a analogia entre arte, filosofia e teologia na Idade Média. São Paulo: Martins Fontes, 2001.

PANOFSKY, Erwin. Significado nas Artes Visuais. 3. ed. São Paulo: Perspectiva, 2001.

WILLIAMS, Raymond. Cultura. São Paulo: Editora Paz e Terra S. A., 2000 .

WÖLFFLIN, Heinrich. Conceitos Fundamentais da História da Arte: o problema da evolução dos estilos na arte mais recente. 4. ed. São Paulo, Martins Fontes, 2000. 


\title{
LOOKS FOUR: ANALYSIS OF SOME THEORETICAL-METHODOLOGICAL CONTRIBUTIONS TO THE SOCIOLOGY OF CULTURE AND SOCIAL HISTORY OF ART IN THE 20th CENTURY
}

\begin{abstract}
The comparative study about some major authors associated with the Sociology of Culture and Art of Social History points to the spread of the debate within these fields of research throughout the twentieth century. Such complexity, in turn, had been expressed by the expansion of the documentary, as well as the introduction of new issues, problems and methodological approaches in both areas of knowledge. This article presents and lists some views around two important issues for both art historians and sociologists of culture: the discussion to the idea of culture and the different understandings about the relationship between aesthetic forms and social processes. To accomplish this discussion, this paper analyzes the use of sources and the methods used by four scholars identified with different intellectual traditions: Wölfflin Heinrich (1864-1945), Erwin Panofsky (1892-1968), Mikhail Bakhtin (1895-1975) and Timothy James Clark (1943).
\end{abstract}

Keywords: Sociology of Culture; Art History; Theory and Methodology. 